the baseline fibrinogen concentration and decrease blood loss.

Finally, the relationship between the plasma fibrinogen concentrations, measured using either the Clauss method or maximal clot firmness measured using FIBTEM (a ROTEM assay; Tem International, Munich, Germany), and early postoperative blood loss was recently studied in the pediatric population. ${ }^{6}$ Plasma fibrinogen concentrations $<1.5 \mathrm{~g} / \mathrm{L}$ and maximal clot firmness on fib-tem $<3 \mathrm{~mm}$ predicted postoperative blood loss with good sensitivity and specificity. Because the test is available rapidly at the bedside, the maximal clot firmness on fib-tem should be preferred to guide fibrinogen replacement. I would have been interested to read what fibrinogen level measured immediately after bypass predicted for a second administration of cryoprecipitate. Knowing this could have improved the transfusion algorithm in children undergoing cardiac surgery as suggested in Figure 1.

David Faraoni, MD, FCCP Department of Anesthesiology Queen Fabiola Children's University Hospital

Free University of Brussels Brussels, Belgium

\footnotetext{
References

1. Galas FR, de Almeida JP, Fukushima JT, Vincent JL, Osawa EA, Zeferino S, et al. Hemostatic effects of fibrinogen concentrate compared with cryoprecipitate in children after cardiac surgery: a randomized pilot trial. $J$ Thorac Cardiovasc Surg. April 18, 2014 [Epub ahead of print].

2. Lee SH, Lee SM, Kim CS, Cho HS, Lee J-H, Lee $\mathrm{CH}$, et al. Fibrinogen recovery and changes in fibrin-based clot firmness after cryoprecipitate administration in patients undergoing aortic surgery involving deep hypothermic circulatory arrest. Transfusion. 2014;54: 1379-87.

3. Levy JH, Szlam F, Tanaka KA, Sniecienski RM. Fibrinogen and hemostasis: a primary hemostatic target for the management of acquired bleeding. Anesth Analg. 2012;114:261-74.

4. Rahe-Meyer N, Solomon C, Hanke A, Schmidt DS, Knoerzer D, Hochleitner G, et al. Effects of fibrinogen concentrate as first-line therapy during major aortic replacement surgery: a ran-
}

domized, placebo-controlled trial. Anesthesiology. 2013;118:40-50.

5. Martini J, Maisch S, Pilshofer L, Streif W, Martini W, Fries D. Fibrinogen concentrate in dilutional coagulopathy: a dose study in pigs. Transfusion. 2014;54:149-57.

6. Faraoni D, Willems A, Savan V, Demanet H, De Ville A, Van der Linden P. Plasma fibrinogen concentration is correlated with postoperative blood loss in children undergoing cardiac surgery: a retrospective review. Eur J Anaesthesiol. 2014; 31:317-26.

http://dx.doi.org/10.1016/ j.jtcvs.2015.01.053

\section{CLOSING THE STABLE DOOR BEFORE THE HORSE LEAVES} To the Editor:

In response to the excellent article, "Povidine iodine: The new solution for mesothelioma?" by Valerie W. Rusch, ${ }^{1}$ indicating favorable outcomes with addition of hyperthermic povidone iodine to the multimodality approach to malignant pleural mesothelioma, it might also be considered that there are no recorded cases of mesothelioma in the medical literature after earlier pleurodesis by introduction of pleural sclerosants, including povidone iodine, to prevent recurrent pneumothorax in young men. ${ }^{2}$ In view of the very large number of such individuals worldwide who have undergone this procedure during the last 70 years and universal awareness of a potential risk of inducing malignancy, it would seem reasonable to suspect that the changes these sclerosants produce in the parietal pleura may in fact prevent development of mesothelioma. If this is correct, a younger individual with evidence of asbestosrelated pleural plaques might choose simple pleurodeses to remove the long-term slight but real threat of development of mesothelioma.

Vincent Acton, MBBS (Syd), FRANZCR Radiology Private Practice Sydney, Australia

\section{References}

1. Rusch VW. Povidone iodine: the new solution for mesothelioma? J Thorac Cardiovasc Surg. 2015; 149:567-8.

2. Middleton EA, Daniel JC, Knox KS, Williams K PET positive pleural plaques decades after pleurodesis: mesothelioma? Southwest J Pulm Crit Care. 2011;2:9-16.

http://dx.doi.org/10.1016/ j.jtcvs.2014.11.007

\section{COMPUTED TOMOGRAPHY OR CHEST RADIOGRAPH SURVEILLANCE FOLLOWING STAGE I NON-SMALL CELL LUNG CANCER RESECTION? \\ To the Editor:}

We read with interest the article by Crabtree and colleagues ${ }^{1}$ about appropriate radiologic surveillance following lung resection for stage I non-small cell lung cancer (NSCLC). This issue is strictly linked with another topic: lung cancer screening. In fact, postoperative surveillance should focus not only on early detection of lung recurrences but also on new primary lung cancers.

The authors' most significant results are that in the computed tomography (CT) group, time to diagnosis of new malignancy was shorter and that $49 \%$ of patients affected by new malignancy were asymptomatic (vs 19\% in the chest radiograph group). In fact, early diagnosis and symptoms absence should be correlated with more possibilities of an effective therapeutic strategy. Surprisingly, the authors found that the proportions of patients referred to curative therapy for new malignancy were the same in the 2 groups. Moreover, overall survival in patients developing successive malignancy were not associated with radiologic surveillance. These data could suggest that $\mathrm{CT}$, although associated with some advantages, has the same outcomes as chest radiograph in surveillance of patients submitted to lung resection for stage I NSCLC. Moreover, these results are inconsistent with the National Lung Screening Trial, which showed in a larger population 